\title{
DESIGN AND CORE COMPETENCY, THE MISSING LINKS
}

\author{
Eric Bonjour ${ }^{1}$, Jean-Pierre Micaëlli ${ }^{2}$, Onanong Hlaoittinun ${ }^{1}$ And Ioana Deniaud ${ }^{3}$
}

\author{
(1)Laboratoire d'Automatique de Besançon - UMR CNRS 6596-ENSMM - UFC \\ 24 rue Alain Savary, 25000 BESANCON (France) - ebonjour@ens2m.fr \\ (2)RÉCITS Research Team UTBM, 90010 Belfort (France)-jean-pierre.micaelli@utbm.fr. \\ (3)Laboratory, Université Louis Pasteur, 61 avenue de la Forêt Noire, 67085 Strasbourg (France) - \\ deniaud@cournot.u-strasbg.fr.
}

\begin{abstract}
Designing in an industrial context is a very complex activity. It needs the integration of heterogeneous knowledge or skills, to transform a set of ill-defined requirements into an artefact that satisfies esthetical, functional, technical, economical criteria. Design process optimization with methods like system engineering and core competency building are key issues for managers of product development process, design skills networks, communities of design practices... In the literature, these issues have been dealt with separately. In this paper, we propose a framework of reference that helps us to explicit the content of the core design competency. This framework is a first step beyond an efficient competency based management of design structures. Copyright $\mathbb{C} 2007$ IFAC
\end{abstract}

Keywords: Competency, Design, DSM, Organization, Strategy

\section{INTRODUCTION}

Designers have to develop products with drastic performances related to cost, delay, quality, environmental and safety regulations, creativity... In this particular context, special attention has been drawn both to the deeper understanding of the design activities and to the development of more and more abstract tools (Stankiewicz, 2000) to assist engineers and managers in improving their activities. For example, since the 90 's, firms have been improving their design structures (projects, teams, process...) performances by using new approaches such as Systematic Design (Pahl, Beitz, 1996), Concurrent Engineering (Prasad, 1996), System Engineering (INCOSE, 2006) and new tools like Design Structure Matrix (Ulrich, Eppinger, 2000), DFX, CAD-CAM, digital mock up, CSCW, PDM... In the same time, the focus of the strategic management has been changing. Authors like Prahalad and Hamel (1990) introduce the idea that the target of the strategy is not the product and its market, but the core competency that the firm can use and improve. Today the question is how to link these two aspects. Or, in other words, what is the appropriate framework for managing core design competency? A recent survey (Boucher, Bonjour, Grabot, 2007) of the formalisation and integration of competence-oriented concepts within performance management points out interesting perspectives, specially a lack of integration between the various levels of competence management. In order to give a response to these difficult questions, two points have to be de-locked. The first one is to define what a competency is, especially with a systemic approach. The second one concerns what a core design competency is. The identification of core design competency is quite difficult because the communities of mechanical engineering, industrial engineering, knowledge management... suffer from a lack of global concepts and integrated models.

\section{DESIGN COMPETENCY, A SYSTEMIC APPROACH}

Competency is not an atom but a system with several interrelated components. To understand it globally, it is convenient to build a framework that includes eight main elements:

\subsection{Actor}

This is a individual (here, designers) or a group ("acting unit", Parsons, 1965) who is in charge of performing a mission or a set of missions and who acts permanently, temporarily or occasionally at the service of a considered organization (design structures, in our context: department, skill network, project, team (Ullrich, Eppinger, 2000), process, community...). There are collective actors of various sizes: from binomials to large organizations. To be more efficient, a collective actor has to be managed and structured (Chandler, 1977). 


\subsection{Tasks}

The actor realizes tasks, that is: "what is to do in the system". In the case of design, it is a set of processing: information processing and/or problem solving (Simon, 1997). It concerns a set of given planned objects (material or immaterial inputs, prototypes or requirements for example). The objective of the given task is to produce a set of expected outcomes (resulting objects or outputs): a sheet of requirements, a architectural diagram (SysML, 2006), a calculus or a simulation, a virtual or real prototype... Process is a scheduled organization of tasks which have similar objectives on the same flow or the same type of flow (material, information, knowledge, decisional objects...).

\subsection{Situation}

It corresponds to the context of actor's tasks. In an internal point of view, situation is what is meaningful for the actor in his environment. In an external point of view, it includes the actor himself, the "alters" (Parsons, 1965) who acknowledge what he does (synonymous: his behaviour) and some shared objects. A design situation is composed with designers, professionals of all kind (managers, specialists of marketing, cost engineers, process engineers...) and objects like requirements, standards, prototypes, ready-made solutions... The situation is steadily changing. In a normal, foreseeable situation, it enables the actor to understand, to plan and to perform the mission. But the situation could be characterized by its variability and by the gap between the forecasts and the actual context (cognitive dissonance). The given actual inputs are different from the given planned inputs (task variability), unpredictable events may occur... Of course this is the case in every design situations: requirements change, problems are re-set (Simon, 1997), anticipated solutions are not so good... The actor has an intelligent behaviour. He is permanently in interaction with elements of the situation.

\subsection{Mission}

A mission is a kind of "transaction" (Commons, 1989). It is defined by an alter

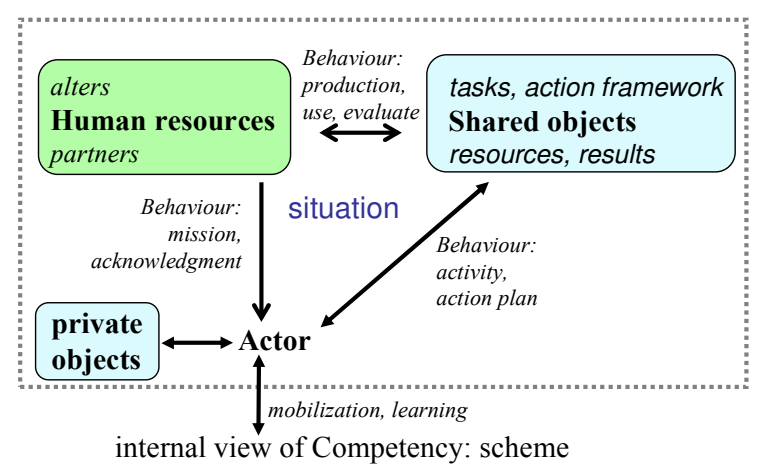

(customer, manager, partner...) and affected to an actor under his responsibility. He is entrusted with this mission. A mission is characterized by a (set of) task(s) and an action framework. In design process, the content of the mission concerns more "the why" (task goals with requirements, constraints, evaluation criteria...) than "how" (solution, procedure...). So the actor has the responsibility to fulfil the mission by determining the relevant organization of finalized activity, that is, an action plan.

\subsection{Action framework}

Because of his "bounded rationality" (Simon, 1997), the alter can not determine a complete characterization of the prescriptive situation. He has to choose relevant and critical elements (for instance, available technical resources, potential partners and supports, management procedure) according to the task of the mission and to the actor's autonomy. In design process, due to the situation complexity and the high level of skills needed, the actor (designer) has a large autonomy to perform his mission.

\subsection{Activity}

It corresponds to how the actor performs his mission in the actual situation. Activity has two aspects: external (behavioural) and internal (cognitive). The former may be modelled by means of a mission and the latter, by means of an action plan.

\subsection{Competency-external view}

An external view considers competency as a black box which provides for a successful finalized activity, in answer to two inputs: on the one hand, activity aims, i.e. expected results, on the other hand, a determined action framework, i.e. key-elements of the situation. If these inputs are specified in terms of mission, the associated competency is called operational competency. An operational competency is an appreciation or "acknowledgement" made on a given actor, by a determined judge related to a defined mission (or finalized actions). It is related to a successful mission or a class of couples a aims or tasks; action framework\} (Bonjour, Dulmet, Lhote, 2002).

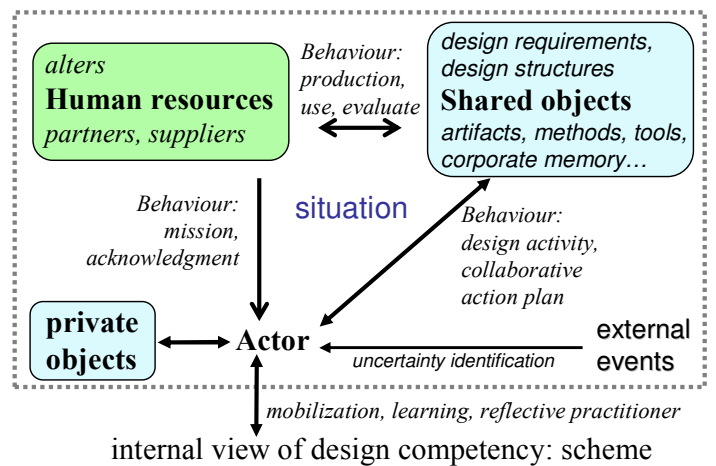

internal view of design competency: scheme

Fig.1: Architecture of the competency system 


\subsection{Competency-internal view}

Competency is not only a behavioural concept. It is also a cognitive concept. So, an internal view considers it like an entity supported by a cognitive structure which the psychologist Jean Piaget (1969) had called "scheme". The scheme activation corresponds to the "mobilization" and dynamic organization of a set of heterogeneous cognitive resources that leads to the production of an acknowledged performance, in the framework of a finalized activity and a particular class of situations (Bonjour, Dulmet, Lhote, 2004). Thanks to its competency, an actor transforms a mission, with which he had been entrusted, into a successful flow of action that will achieve expected results. The external effects of the cognitive view that can be observed and made explicit may be modelled by an action plan. The architecture of the competency system describes in Fig. 1.

This system is illustrated in Fig.2 in the case of an action plan (activity graph) of an individual system architect in the automotive industry. His mission is to develop the front axle tree of the chassis, to allocate volumes and to specify interfaces (Bonjour, Dulmet, Lhote, 2002).

\section{A NEW OBJECT, THE CORE DESIGN COMPETENCY}

It is usual to use the concept of competency to describe the sole operational competency: the individual competency of a specific designer, in our case. If the actor (designer) is not an individual but an acting organizational unit, we need to define new attributes to characterize his competency. In that sense, a core competency is a competency associated to a collective actor. In a market economy system, the core competency can be seeing as an intangible asset of the firm (Hamel, Prahalad, 1990):

1) it concerns several acting units, and not only individuals, experts for example.

2) the acting units have to produce both technically and economically efficient results.

3) the situation is a competitive one, with current or potential competitors (substitutes included) who target the same customers and/or have the same suppliers or founders (Porter, 1985).

4) the mission is defined in terms of "managerial transaction" (Commons, 1989). It contains either financial, marketing, organizational criteria or aspects (Kaplan, Norton, 2004). The acknowledgment is not only defined by the manager but also by the customers or the competitors. The criteria can be "cost" or "differentiation advantage" (Porter, 1980).
5) the action framework has to be a "black box" for competitors (it is difficult to imitate it or the imitation is not credible) and a "transparent box" for managers.

6) in that way, core competency requires closed links between operational designers (acting units as it is) and managers (acting units as it be), understood as organizational designers.

7) the activity and the knowledge related to it are not trivial. The knowledge can be very specific or it can combine different kinds of elementary knowledge (Nonaka, Taleuchi, 1995). In every cases it is built and developed by acting (learning by acting) and using some expensive resources;

8) in an external view, core competency gives a dynamic and sustainable (Teece, Pisano, Shuen, 1997) "competitive advantage" (Porter, 1985). It allows an access to a wide variety of markets and makes, for each of them, a significant contribution to the "margin" of the whole "value chain" (Porter, 1985). In other words, it allows outperforming its competitors and reinforcing its own internal or transactional (bargaining with suppliers) strengths.

9) in an internal point of view, it is not only a single combination of individual competencies, but a complex (Simon, 1997) and evolving (Ethiraj, Levinthal, 2004) structure. By the way the building process of the core design competency is "embedded" and allows "causal ambiguity" by the competitors' point of view (Barney, 1991).

In the case of design, the paradigm of the core competency can be declined as follows. Of course, the acting units concerned are all the design structures intra (departments, lightweight projects, teams...) or inter-firm (communities, value networks, skill networks...). The way of managing them differs. Their efficiency can be defined also in different ways. For example, a design department or a skill network has to develop, extend, make sustainable, socialize (Nonaka, Takeuchi, 1995) ..., basic competencies. A design project or every "adhocratic" (Mintzberg, 1979) structure has to be efficient in short-term terms such as reactivity.

The expected results of an internal design structure can be defined with several criteria. For example, an automaker wants his design acting units to have the abilities to develop modular architectures (Ullrich, Eppinger, 2000). Thus it allows either differentiation (economies of scope), economies of scale, learning curve obtaining, trade off between suppliers, flexibility, perennially, technical line obtaining... The development of some critical parts of the vehicle remains internal. For example, the automaker can focus its resources to the high level layers of the System Engineering (INCOSE, 2006): 
marketing and functional specifications, architecture, final tests... Or he may also build core design competence related to very precise and critical components such as powertrain if gradeability is a distinctive consumer's service. In every case, the design competence is used and produced in a complex and ambiguous way. For example, Fig. 3 shows a very simplified DSM that describes the cross links between design teams responsible for the front wheel drive system development and the whole design teams implied in the vehicle development (Harmel, Bonjour, Dulmet, 2006). The replication of a so complex architecture is not easy. Furthermore the quality of the links depends on the past common projects shared by the different design teams. Least but not least, the core design competence of the automaker concerns very specific domains (so specialised knowledge) and integrative modules (so architectural knowledge).

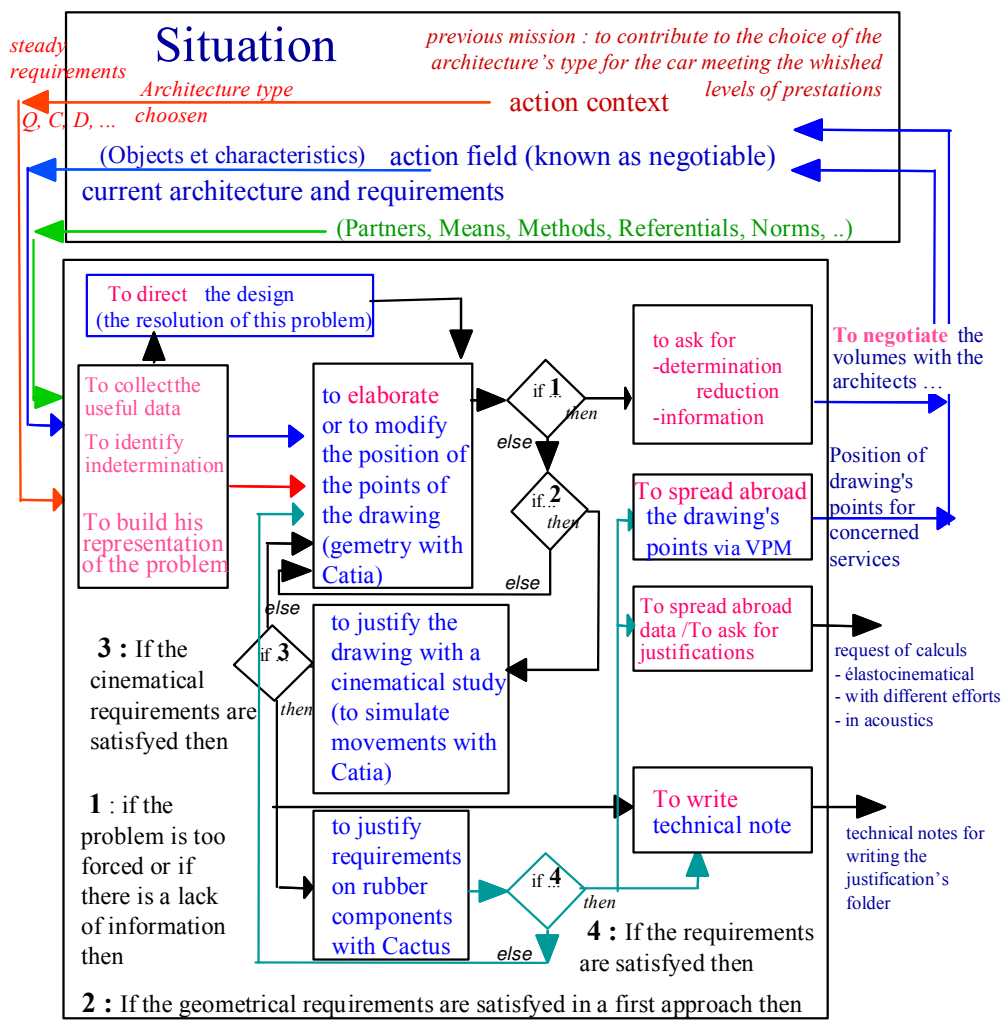

Fig.2: An example of an action plan supporting an individual designer's competency

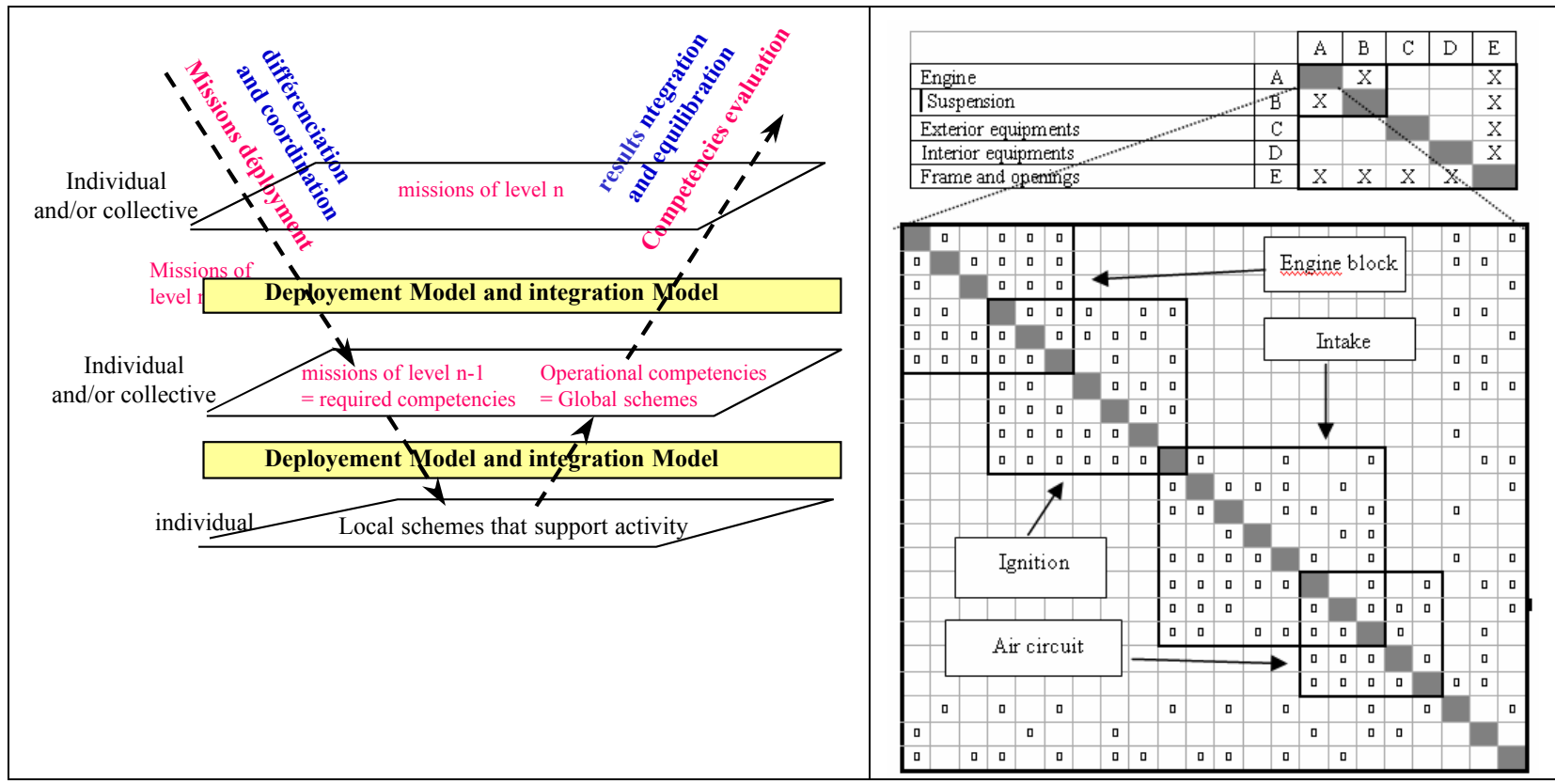

Fig.3: DSM as a mapping of a collective designer and a core design competency and as a deploymentintegration model 


\section{CONCLUSION}

This short communication has tried to link two domains that have been dealt with separately by researchers. The first one concerns the field of industrial engineering, with its main purpose that is to optimize operational processes such product development, supply chain... The second is related to the new perspectives of strategic management opened by the seminal work of Harmel and Prahalad (1990). We have proposed a framework of reference that helps us to explicit the content of the core design competency. This systemic framework has to be seeing as a first step beyond an efficient competency based management of design structures. Matrix-based representations (with clustering algorithms) seem to be very promising and useful to support the core competency deployment from collective actors to individuals, to structure them and then, to support the integration of their contributions at different layers of the design structures. If our clarification of the concept of core design competence is useful, many questions remain outstanding. What is the portfolio of structures convenient for building strategic competencies? How to manage them, especially in the case inter-firms structures? How to appropriately integrate the strategic management level and the operational design level through the organizational/structural management level?

\section{REFERENCES}

Bonjour, E., Dulmet, M., Lhote, F., (2002), “An internal modeling of competency, based on a systemic approach, with socio-technical systems management in view", IEEE Conference on Systems, Man and Cybernetics, Hammamet, Tunisia.

Bonjour, E., Dulmet, M., Lhote, F., (2004), "Models to split and to integrate competencies systems in design activities management", Proc. 11th IFAC Symposium on INformation COntrol in Manufacturing, INCOM'2004, CD ROM, Salvador da Bahia, Brazil, April 5-7, 2004, 6 p.

Boucher, X., Bonjour, E., Grabot, B., (2007), "Formalisation and use of competencies for industrial performance optimisation: a survey", Computers in industry, Volume 58, Issue 2, February 2007, Pages 98-117

Chandler, A., (1977), The Visible Hand: The Managerial Revolution in American Business, Belknap Press.

Commons, J-R., (1989), Institutional Economics: Its Place in Political Economy, Rutherford, M. (Ed.), New Brunswick (NJ): Transaction Publishers.

Ethiraj, S., Levinthal, D., (2004), "Bounded Rationality and the Search for Organizational Structure: An Evolutionary Perspective on the Design of the Organizations and Their Evolvability", Administrative Science Quarterly, 50(4), pp.404-437.
Hamel, G., Prahalad, K., (1990) "The Core Competency of the Corporation", Harvard Business Review, 68(3), pp.79-93.

Harmel, G., Bonjour, E., Dulmet, M., (2006), "A method to manage the co-evolution of product and organization architectures", IMACS-IEEE Multiconference on Computational Engineering in Systems Applications, CESA 2006, October 4-6, Beijing, China.

Kaplan, R., Norton, D., (2004), Strategy Maps: Converting Intangible Assets into Tangible Outcomes, Boston (MA): Harvard Business School Press.

Mintzberg, H., (1979), The Structuring of Organizations, Englewoods Cliffs (NJ): Prentice Hall.

Nonaka, I., Takeuchi, H., (1995), The knowledgecreating company: how Japanese companies create the dynamics of innovation, Cambridge (MA): Oxford University Press.

Pahl, G., Beitz, W., (1996), Engineering Design: a Systematic Approach, Berlin (D): SpringerVerlag.

Parsons, T., (1965), Toward a general theory of action: Theoretical foundations for the social sciences, New York (NY): Harper \& Row.

Piaget, J., (1969), La Construction du réel chez l'enfant, Neuchâtel $(\mathrm{CH})$ : Delachaux et Niestlé.

Porter, M., (1980), Competitive Strategy, New York (NY): Free Press.

Porter, M., (1985), Competitive Advantage, New York (NY): Free Press.

Prasad, P., (1996), “Concurrent Engineering fundamentals: integrated product and process development", Prentice-Hall international series in industrial and systems engineering, New Jersey (NJ): Prentice-Hall.

Simon, H-A., (1997), The Sciences of the Artificial, Cambridge (MA): MIT Press.

Stankiewicz, R., (2000), "The Concept of «Design Space»", Ziman, J. (Ed.), Technological Innovation as an Evolutionary Process, Cambridge (UK): Cambridge University Press, pp.234-247.

SysML, (2006), OMG Systems Modeling Language (OMG SysML ${ }^{\text {TM}}$ ) Specification - Final Adopted Specification, Object Management Group, november.

Teece, D., Pisano, G., Shuen, A., (1997), "Dynamic Capabilities and Strategic Management", Strategic Management Journal, 18(7), pp.509533.

Ulrich, K-T., Eppinger, S-D., (2000), Product Design and Development, New York (NY): McGraw-Hill. 